\title{
Corruption and Deforestation: A Differential Game Model
}

\author{
Cassandro Mendes \\ University of Cabo Verde (School of Business and Governance), Cape Verde \\ E-mail: cassandromendes@ hotmail.com
}

\author{
Sabino Junior \\ Federal University of Rio Grande do Sul, Brazil \\ E-mail: sabino@ppge.ufrgs.br \\ Fabricio Tourrucôo \\ Federal University of Rio Grande do Sul, Brazil
}

Received: March 11, 2016

Accepted: April 2, 2016

doi:10.5296/ber.v6i1.9166

URL: http://dx.doi.org/10.5296/ber.v6i1.9166

\begin{abstract}
Deforestation is a global issue and recently has been given much attention by governments and international institutions. The present paper aims to present a simple theoretical model on the relationship between corruption and deforestation. To model such relationship, we used differential games. Our model suggests that corruption increases deforestation. Moreover, the salary paid in the public sector may be an important tool to fight deforestation in development countries.
\end{abstract}

Keywords: Deforestation, Corruption, Differential game

\section{Introduction}

The relationship between corruption and tropical deforestation is not a new global issue, many empirical works highlights this relationship, see for instance Koyunen and Yilmaz (2009), Damania (2002), Pellegrini and Gerlagh (2006a), and Amacher (2006). Pellegrini e Gerlach (2006a) analyzed the impact of the entrance of new countries in the Europe union on the environmental policies. They found that the corruption is the main responsible for the 
effectiveness of the environmental policies in these countries. Koyunen e Yilmaz (2009) analyzed, in 100 countries, the impact of corruption in the deforestation. They found a strong correlation between both variables. Pellegrini (2006b) analyzed the impact of corruption and democracy on deforestation. He found that corruption was a significant variable to explain the different deforestation rate between the countries. Mendes and Porto (2012), used data from Brazilian municipalities to show that that corruption is a significant variable, and therefore should not be neglected by the Brazilian government.

Recent study from UNEP (2012) highlights the direct impact of organized crime and corruption on the illegal deforestation. According with this institution, organized crime has been responsible for more than $90 \%$ of all deforestation occurred in many countries. Despite the huge amount of empirical studies on the relationship between corruption and deforestation, we didn't find any theoretical work that shows how this relationship works. Thus, this paper aims to fill this gap in the literature on deforestation.

The paper is organized as follow: the following section provides the core assumptions used to build the model. In the third section we derive the Stackelberg equilibrium, and, finally, section fourth concludes.

\section{The model}

To model the relationship between corruption and deforestation, we used stackelberg differential game ${ }^{1}$. We suppose that there are two players in the game: the landowner and the official from the government. The roles of the game, namely the salary system, penalty function, and the surveillance of the land, are controlled by the government. However, there is no auditing, in the field, on the official's work. The governmental official (GO) earns a constant salary, in each $t \in[0, T]$. Besides the GO, the other player is the landowner, whose objective is to find the optimal way for his profit.

The informational structure used to solve this model is open-loop equilibrium à la stackelberg. We suppose that the leader in this game would be the landowner and the follower would be the GO. It is plausible to suppose this structure, considering that in this kind of illegal behavior we expect that the landowner will interact with the official to see the amount of bribe to give; therefore he is the leader. To keep the explanation of the model simple we decided to list the main assumptions used:

Assumptions-1: Monetary penalty function : $F(t)=f(t) Q(t) E(t)$,

Assumption-2: The Kinematic equation is supposed to be: $\dot{X}(t)=-Q(t)+r X(t)$,

Definition-1: The inverse demand function is defined as: $P(t)=\bar{p}-\theta Q(t)$,

\footnotetext{
${ }^{1}$ The differential game has been used to model the phenomenon of deforestation, see for instance Fredj et al (2004), and Herrán et al. (2006). However, none of the previous work has highlighted the impact of corruption on deforestation.
} 
We suppose a linear penalty function, where $f(t)$ denotes the penalty rate, defined by the government, for each $t \in[0, T]$. If we suppose that the government is a passive agent in the relationship, therefore, we must also suppose that the penalty rate is constant over time, i.e., $f(t)=\bar{f}$ (initially the government announces its penalty policy, and this policy will remain until the final period $\left.{ }^{2}\right)$. $Q(t)$ denotes the quantity of timber logged. According with the penalty function, the higher the quantity arrested, $Q(t)$, the higher is the monetary value of the fine (adjusted by the penalty rate $f$ ). In the present case, we suppose that all the quantity of wood, illegally harvested, is arrested. $\mathrm{E}(\mathrm{t})$ represents the effort applied by the GO. If no effort is applied by the GO no illicit activity is found - in this case the landowner cannot be fined.

$\mathrm{X}(t)$ is the quantity of forest. We supposed that the forest naturally grows at constant rate $r$. $\theta, \bar{p}$ are the positive parameters of the inverse demand function.

Assumption-3: The Official's utility is disjointedly given by the consumption and the cost of his work (effort) at each time.

$$
U(c(t), E(t))=c(t)-v(E(t))
$$

We suppose that the effort, applied by the official, generates a cost, namely physical cost for being in field doing surveillance. The cost function is $v($.$) , which is supposed to satisfy the$ following conditions: $v^{\prime}()>0,. v^{\prime \prime}()>$.0 . That is, the higher the effort applied, by the landowner, the higher is the cost, at an increasing rate.

Assumption-4: We suppose that the consumption is linear in its arguments. We define the consumption at each $t \in[0, T]$, as $c(t)=w_{0}+B(t)$. Where $w_{0}$ indicates the constant salary paid for each $t \in[0, T]$. However, the GO can be bribed by the landowner and receive a non-negative amount, $B(t)$ at each $t$.

Asssumption-5: We define the bribe as function of the amount of monetary penalties.

$$
B(t)=b(t) F(t)
$$

Where $b(t)$ represents the proportion of the monetary penalties received by the official.

\footnotetext{
${ }^{2}$ In a good sense, this is the situation in most part of the countries. For example, in Brazil each new government usually begins announcing new environmental policies for all legal period (five years until the next elections).
} 
Hence, it is expected that $b \in[0,1]$ at each $t$. Since we expect that, the higher the bargaining power of the official the higher will be the bribes paid to him, this parameter can be viewed as the bargaining power of the official. In others words, $b(t)$ represents the measure of the official power to collect more bribes. For sake of simplicity, we suppose that the bargaining power is constant over the specified period, hence $b(t)=b_{0}$. Therefore, the bribe function can be denoted in the following way

$$
B(t)=b_{0} f_{0} Q(t) E(t)
$$

Remark-1: in order to allow the game to be played between the landowner and the official, we defined $b_{0} \in[0,1)$, that is, the bargaining power needs to be less than one unity. If we had $b_{0}=1$, that would mean that the landowner would pay all the penalties to the official.

\section{The stackelberg equilibrium ${ }^{3}$}

The aim of the official is to choose the level of effort to maximize his gain over a finite period of time ${ }^{4}$.

$$
V=\max _{\{E(t)\}} \int_{0}^{T}\left[\left(w_{0}+f_{0} b_{0} E(t) Q(t)\right)-v(E(t))\right] d t
$$

As a leader, the landowner will incorporate the optimum official strategies in his optimization problem. The goal of landowner is to choose the quantity of timber to maximize his profit over the defined time horizon

$$
Z=\max _{\{Q(t)\}} \int_{0}^{T}\left[R(t)-b_{0} F(t)\right] d t+\varphi X(T)
$$

Where $\varphi X(T)$ denotes, a linear, scrap value function, and $\mathrm{R}(\mathrm{t})$ is the revenue function.

To obtain the optimal path for his control, we applied the maximum principle, and the model is solved backwards. We first solved the problem of the official, and after the problem of the landowner. The stackelberg open-loop equilibrium for this game will be given by the

\footnotetext{
${ }^{3}$ The use of the open-loop structure reserves some explanation: usually as demonstrated by Sethi et al. (2007) the open-loop equilibrium is time inconsistent given the interest of the leader to change his strategies at any time $t \in(0, T]$. However, we suppose that the leader (landowner) can credibly pre-commit to his strategies at the beginning of the game. This approach has been applied for many works in the literature (Sethi et al., 2007).

${ }^{4}$ In the present model we suppose that the time is finite, given that we are analyzing the government policies in one period after the elections.
} 
pair of time-dependent strategies:

$$
\begin{aligned}
Q(t) & =\frac{\bar{p}-\varphi e^{r(T-t)}}{2 \theta+f_{0}^{2} b_{0}^{2}} \\
E & =\frac{b_{0} f_{0}\left[\bar{p}-\varphi e^{r(T-t)}\right]}{4 \theta+2 f_{0}^{2} b_{0}^{2}}
\end{aligned}
$$

Therefore, the forest dynamics is explained through the equation (8).

$$
X(t)=\frac{2 r x_{0} e^{r t}\left(2 \theta+f_{0}^{2} b_{0}^{2}\right)+2 \bar{p}\left(1-e^{r t}\right)+\varphi\left(e^{r(T+t)}-e^{r(T-t)}\right)}{2 r\left(2 \theta+f_{0}^{2} b_{0}^{2}\right)}
$$

Thus, at final period the stock of forest will be given by

$$
X(T)=\frac{2 r x_{0} e^{r T}\left(2 \theta+f_{0}^{2} b_{0}^{2}\right)+2 \bar{p}\left(1-e^{r T}\right)+\varphi\left(e^{2 r T}-1\right)}{2 r\left(2 \theta+f_{0}^{2} b_{0}^{2}\right)}
$$

Hence, for the present model we find:

Result-1: From equation (7) we realize that effort applied by the governmental official depends, essentially, of the amount of bribe, the quantity of timber, his bargaining power, and the penalty rate implemented by the government.

Proof: see Appendix A

The quantity of timber logged depends positively of the price in the market. Moreover, the quantity of timber will be affected by the penalty rate and the official bargaining power. If we increase the penalty rate or the bargaining power of the official, the quantity logged will decrease. These results are intuitive, given that the official have a real appraisal of the illicit act, increasing the bargaining power will increase the landowner cost, hence lowering the profit.

The amount of bribe that the official will receive will depend on the amount of penalties, and the latter will depend on the amount logged, hence, the agent will apply more effort to discover the illicit act.

Result-2: The presence of corruption will decrease the stock of forest in the final period (see equation (10)).

Proof: see Appendix A 


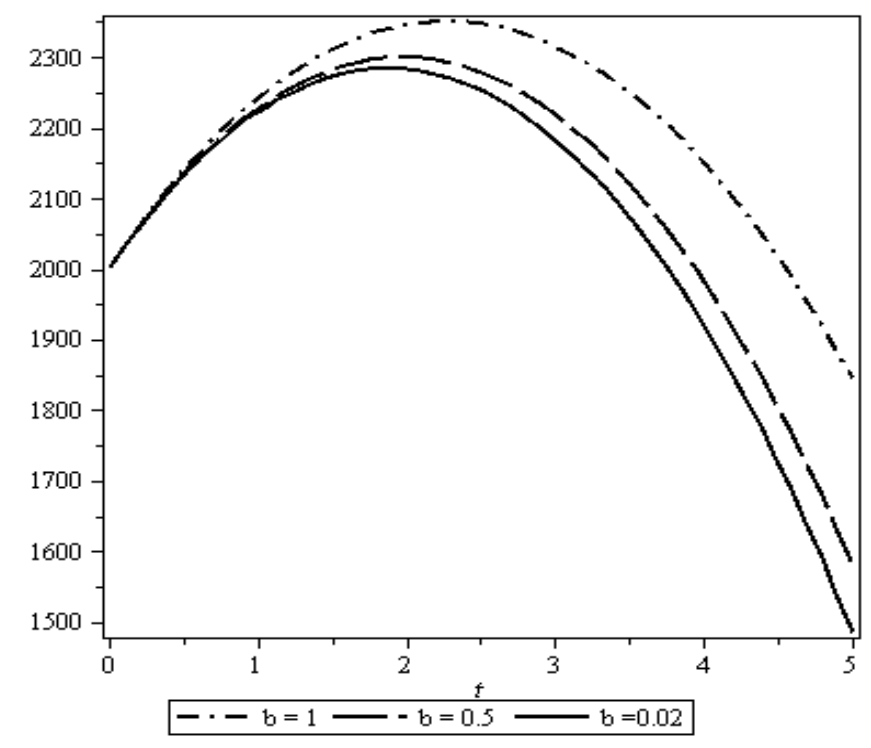

Figure 1. Stock of Forest over period: The effect of different bargaining power.

As we can see in the figure-1, the decline in the bargaining power of the official will increase the quantity of timber logged, and this will lead to a higher level of deforestation, i.e., the stock of forest will tend to zero in a shorter period of time.

If the bargaining power of the official is important for the final stock of forest, it will be interesting to check which variables can influence the bargaining power of the official. It is theoretically appealing to assume that one of the variables that may influence the bargaining power of the official is the salary received by the agent. Intuitively we can expect that: the lower salary received the lower will be the bargaining power of the official. The explanation is very intuitive: when the official has a low salary and finds an illicit act, the landowner can easily convince him to receive any small amount of bribe- in this case, the GO has relatively more to lose if he does not accept the bribe. On the other hand, if we suppose that the salary is high, the official has little to lose by not accepting the bribe - in this case the landowner's cost to convince the GO must be higher. This inverse relationship, between corruption and salaries, has been highlighted in the literature, see for instance Tanzi (1998). We supposed a linear bargaining function, which satisfies the following conditions i.e., $b_{i}=\sigma(w), a n d \sigma_{w}>0, \sigma_{w w}=0$. Thus,

$$
\frac{\partial X(T)}{\partial b_{0}}=\frac{-\left[2 \bar{p}\left(1-e^{r T}\right)+\varphi\left(e^{2 r T}-1\right)\right]\left[4 r f_{0}^{2} b_{0}\right.}{\left[2 r\left(2 \theta+f_{0}^{2} b_{0}^{2}\right)\right]^{2}}>0
$$

Where $w$ represents the salary received by the GO.

Result-3: In the presence of potential corruption, the static comparative shows that the salary scheme implemented by the government in the public sector, will determinate the bargaining 
power of the official, and indirectly the stock of forest in final period.

Proof: see Appendix A

Mathematically we would have:

$$
\frac{\partial X(T)}{\partial w}=\frac{\partial X(T)}{\partial b}\left[\frac{\partial b}{\partial w}=\frac{-2\left[\bar{p}\left(1-e^{r T}\right)+\varphi\left(e^{2 r T}-1\right)\right]\left[4 r f_{0}^{2} b_{0}\right) \sigma_{w}(.)}{\left[2 r\left(2 \theta+f_{0}^{2} b_{0}^{2}\right)\right]^{2}}>0\right.
$$

The results show that the strategy of the government to use a constant salary scheme, may increase the possibility of bribes. Our results are similar to corruption literature, in the sense that the salary scheme is a good policy that can be used to avoid the problem of corruption, and in this particular case to fight illegal deforestation.

\section{Conclusion}

There are many empirical papers that analyses the impacts of corruption in the deforestation. However, lacks theoretical works on the field. In this paper we developed a theoretical model to explain the dynamics of between corruption and deforestation. The dynamics of our model suggests that corruption is an important variable that cannot be neglected by the governments. Moreover, in order to fight corruption (and illegal deforestation) the salary paid in the public sector must be improved.

\section{References}

Amacher S. (2006). Corruption: A challenge for economist interested in forest policy design. Journal of Forest Economics, 12, 85-89. http://dx.doi.org/10.1016/j.jfe.2006.05.002

Damania R. (2002). Environment controls with corrupt bureaucrats. Journal of Environment and Development Economics, 407-427.

Fredj K, Martín-Herrán, G, Zaccour, G. (2004). Slowing deforestation rate through subsidies: A differential game, Automatica, 30, 40, http://dx.doi.org/10.1016/j.automatica.2003.10.020

Koynen C, Yilmaz R. (2009). The impact of corruption on deforestation: a cross-country evidence. Journal of Development Areas, 42, 213-22.

Martín-Herrán G, Cartigny P, Motte E, Tidball M. (2006). Deforestation and foreign transfers: A Stackelberg differential game approach. Computers \& Operations Research, 33, 386-400. http://dx.doi.org/10.1016/j.cor.2004.06.011

Mendes C, Junior S. (2012). Deforestation, economic growth and corruption: a nonparametric analysis on the case of Amazon forest. Applied Economics Letters, 19, 1285-1291. http://dx.doi.org/10.1080/13504851.2011.619487

Pellegrini L, Gerlach R. (2006a). Corruption and Enviromental Policies: what are the implications for the enlarged EU. European Enviroment, 16, 139-154. 
http://dx.doi.org/10.1002/eet.414

Pellegrini L, Gerlach R. (2006b). Corruption, democracy, and environment policy. The Journal of Environment and Development, 15, 332-354. http://dx.doi.org/10.1177/1070496506290960

Sethi S, He X, Prasad A, Gutierrez G. (2007). A survey of stackelberg differential game models in supply and market channels. Journal of Systems Science and Systems Engineering, 16, 385-413. http://dx.doi.org/10.1007/s11518-007-5058-2

Tanzi V. (1998). Corruption around the world-causes, consequences, scopes, and cures, International Monetary Fund Staff Papers, Vol. 45 No. 4.

UNEP (2012). Organized crime trade worth US\$30 Billion responsible for up to $90 \%$ of tropical deforestation. Available at: <www.unep.org.com >. Accessed in 12 November 2012.

\section{Appendix A}

\section{Proof of Result-1}

The dynamic optimization of the official will be

$$
V=\max _{\{E\}} \int_{0}^{T}\left[\left(w_{0}+f_{0} b_{0} E Q\right)-v(E)\right] d t
$$

s.t.

$$
\dot{X}=-Q+r X
$$

Therefore, the Hamiltonian for the official will be

$$
H(.)=w_{0}+f_{0} b_{0} Q e-e^{2}+\mu(-Q+r X)
$$

The dynamic optimization of the landowner will be

$$
Z=\underset{\{Q(t)\}}{\operatorname{MAX}} \int_{0}^{T}\left[R(t)-b_{0} F\left(t, E^{*}\right)\right] d t+\varphi X(T)
$$

s.t.

$$
\begin{gathered}
\dot{X}=-Q+r X \\
\mu(t)=\mu_{0} e^{-t} \\
\pi(T)=\frac{\partial[\varphi X(T)]}{\partial X}=\varphi \\
X(0)=x_{0}
\end{gathered}
$$


Where $\mu(t)$ denotes the co-state variable in the official maximization.

Therefore, the Hamiltonian for the landowner will be

$$
H(t, Q, \pi, X)=\bar{p} Q-\theta Q^{2}-\frac{f_{0}^{2} b_{0}^{2} Q^{2}}{2}+\pi[-Q+r X]+\gamma[-\mu r]
$$

Where $\gamma(t)$ denotes the co-state related with the official co-state variable. By using the First order condition (FOC), and given the transversality conditions A.6 and A.7, is straightforward to obtain the Stackelberg equilibrium. The results from the two Hamiltonian are

$$
\begin{aligned}
& Q(t)=\frac{\bar{p}-\varphi e^{r(T-t)}}{2 \theta+f_{0}^{2} b_{0}^{2}} \\
& E=\frac{b_{0} f_{0}\left[\bar{p}-\varphi e^{r(T-t)}\right]}{4 \theta+2 f_{0}^{2} b_{0}^{2}}
\end{aligned}
$$

Hence, by analyzing the equation A.9, the result follows.

\section{Proof of Result-2}

To determinate the forest path, we must use the kinematic equation, namely

$$
\dot{X}=-Q(t)+r X
$$

Thus,

$$
\dot{X}-r X=-\frac{\bar{p}-\varphi e^{r(T-t)}}{2 \theta+f_{0}^{2} b_{0}^{2}}
$$

Hence, the solution of the forest path is given by

$$
X(t)=e^{\int r d t}\left[B-\int \frac{\bar{p}-\varphi e^{r(T-t)}}{2 \theta+f_{0}^{2} b_{0}^{2}} e^{-\int r d t} d t\right]
$$

By using calculus, and the conditions (A.6) and (A.7), the forest path can be written explicitly as

$$
X(t)=\frac{2 r \Delta x_{0} e^{r t}+2 \bar{p}\left(1-e^{r t}\right)+\varphi\left(e^{r(T+t)}-e^{r(T-t)}\right)}{2 r \Delta}
$$

Where $\Delta=2 \theta+f_{0}^{2} b_{0}^{2}$ 
In the final period, $t=T$, we find that

$$
X(T)=\frac{2 r \Delta x_{0} e^{r T}+2 \bar{p}\left(1-e^{r T}\right)+\varphi\left(e^{2 r T}-1\right)}{2 r \Delta}
$$

Therefore,

$$
\frac{\partial X(T)}{\partial b_{0}}=\frac{-\left[2 \bar{p}\left(1-e^{r T}\right)+\varphi\left(e^{2 r T}-1\right)\right]\left[4 r f_{0}^{2} b_{0}\right.}{[2 r \Delta]^{2}}
$$

Since we must have $Q(t) \geq 0, \forall t \in[0, T]$, and, given that quantity logged is increasing in time, the condition that guarantees the non-negativity constrain is

$$
\frac{\bar{p}}{\varphi}>e^{r T}
$$

Therefore,

$$
2 \bar{p}\left(1-e^{r T}\right)+\varphi\left(e^{2 r T}-1\right)<0, \forall t \in[0, T]
$$

Thus, the result follows, namely

$$
\frac{\partial X(T)}{\partial b_{0}}>0
$$

\section{Proof of Result -3}

From A.16, it is straightforward to obtain the result, given that

$$
\frac{\partial b(w)}{\partial w}>0
$$

Thus,

$$
\frac{\partial X(T)}{\partial b(w)}>0 \rightarrow \frac{\partial X(T)}{\partial w}=\frac{\partial X(T)}{\partial b(w)} \frac{\partial b(w)}{\partial w}>0
$$

\section{Appendix B}

For the numeric simulation presented in the figure-1, the following figures were used:

$$
\begin{aligned}
& \varphi=17000 \quad T=5 \quad \bar{p}=50000 \quad \theta=20 \quad r=0.2 \quad f_{0}=2 \\
& X(0) 20
\end{aligned}
$$




\section{Copyright Disclaimer}

Copyright for this article is retained by the author(s), with first publication rights granted to the journal.

This is an open-access article distributed under the terms and conditions of the Creative Commons Attribution license (http://creativecommons.org/licenses/by/3.0/). 